\title{
Dietary Intakes by Different Markers of Socioeconomic Status: A Cross-Sectional Study
}

\author{
Patricia A. Metcalf ${ }^{1,2 *}$, Robert R. K. Scragg1, Rod T. Jackson ${ }^{1}$ \\ ${ }^{1}$ Division of Epidemiology \& Biostatistics, University of Auckland, Auckland, New Zealand \\ ${ }^{2}$ Department of Statistics, University of Auckland, Auckland, New Zealand \\ Email: ${ }^{*}$ metcalf@auckland.ac.nz
}

Received 31 March 2014; revised 3 May 2014; accepted 10 May 2014

Copyright (C 2014 by authors and Scientific Research Publishing Inc.

This work is licensed under the Creative Commons Attribution International License (CC BY). http://creativecommons.org/licenses/by/4.0/

(c) (9) Open Access

\section{Abstract}

Previous studies show that diet quality varies by socioeconomic gradient. We compared the influence of individual- and area-level socioeconomic characteristics on food choice behavior and dietary nutrient intakes in a cross-sectional survey. Daily nutrient intakes were calculated from a food frequency questionnaire. Participants comprised 4007 people (1915 men, 2092 women) aged 35 to 74 years. Socioeconomic measures included the area-based deprivation NZDep2001, gross household income, education level and the occupation-based New Zealand Socioeconomic Index (NZSEI96). Results: Nutrients expressed as their percentage contribution to total energy intakes and adjusted for age, gender and ethnicity, showed that intakes of cholesterol were higher in the lower income groups, and fibre, alcohol and calcium were lower compared to the highest income group. Similarly adjusted nutrients expressed as their contribution to total energy intakes showed lower alcohol intakes in the lower NZDep2001 classes compared to the highest NZDep2001 class. Lower fruit, cheese, wine, and spirit servings were found in both the lower income and NZDep2001 groups. Lower vegetables, milk and cereal servings were found in the lowest income group compared with the highest. Higher chicken, eggs and bread servings were found in the lowest NZDep2001 group compared to the highest NZDep2001 group. Few statistically significant associations were observed with the NZSEI96 or education. Conclusion: Income was more strongly associated with nutrient intakes and NZDep2001 with food group selections. Lower fruit, cheese, wine and spirit servings in the lower SES strata showed independent associations with income and NZDep2001. However, NZDep2001 and income appear to be measuring different elements of dietary intakes and food group servings, with income being associated with lower vegetable, milk and cereal servings, and increased dietary cholesterol and lower fibre, and calcium intakes and NZDep2001 with increased chicken, eggs and bread servings. More in depth, research into arealevel determinants of diet is warranted.

\footnotetext{
${ }^{*}$ Corresponding author.
} 


\title{
Keywords
}

\author{
Energy Intake, Diet, Fruit and Vegetables, Socio-Economic Position, Education, Income, Area \\ Deprivation
}

\section{Introduction}

Measures of socioeconomic status (SES) that have shown the greatest influence on health in New Zealand include income and poverty, employment and occupation, housing, population-based services, social cohesion and culture, and ethnicity [1]. However, education has been regarded as interchangeable with income and occupation [2], though it has been suggested that income may be a better predictor of health status than any other SES measure [3]. In contrast, Geyer et al. [4] argue that income, education and occupational class cannot be used interchangeably, and that although they are correlated, they measure different phenomena and tap into different causal mechanisms. Few studies appear to have looked at the crude associations with SES and then adjusted simultaneously for the other measures to determine their independent contributions.

We have previously reported that dietary intakes showed a generally more adverse pattern in the lower socioeconomic strata and that the New Zealand Socioeconomic Index (NZSEI96) and education were more strongly associated with food group selections, whereas nutrient intakes were associated with income in a multiracial workforce [5].

The aim of this study was to compare daily dietary nutrients and food group servings per month across the area-based deprivation index NZDep2001, household income, level of education and the New Zealand Socioeconomic Index (NZSEI96) and to determine whether there were differences after adjusting for other measures of socioeconomic status.

\section{Study Population and Design}

\subsection{Subject Selection and Study Design}

The Auckland Diabetes, Heart and Health Survey was carried out between December 2001 and November 2003. Adults aged 35 to 74 were recruited from 2 sampling frames: one was a cluster sample where random starting point addresses were obtained from Statistics New Zealand and the probability of selection was proportional to the number of people living in that mesh block (response rate 61.3\%); and the other was a random sample taken from the November 2000 Auckland electoral rolls stratified into 5 year age bands and included all people living in the Auckland area, but excluding Franklin and Rodney (response rate 60\%). Out of the 4049 participants interviewed, 1408 were from the cluster sample, and 2641 were from the electoral roll. Forty nine people were excluded as they were outside the age range leaving 4020 . A further 13 people did not complete the food frequency questionnaire leaving 4007. These participants comprised $47.8 \%$ males and $52.2 \%$ females; $43.5 \%$ Europeans, 25.0\% Maori, 24.6\% Pacific and 6.9\% Asian people. Ethical Committee approval was obtained from the Auckland Ethics Committees.

\subsection{Data Collection}

Interviews were carried out in halls or clinics close to participant's homes. Personnel were trained in the administration of the questionnaires. Participants filled in a questionnaire which included questions on ethnicity, education level attained, occupation, and gross combined household income. Ethnicity was defined according to the current NZ census [6]. Occupations were first coded using the New Zealand classification of occupations [7]. Occupational class was then assigned as the highest of the participant or their spouse, or for retired people using their main lifetime occupation using the New Zealand Socioeconomic Index (NZSEI96) [8]. NZSEI96 was then transformed into discrete "occupational classes" as proposed by Davis et al. [8]. These classes are comprised of: Class 1-legislators and administrators; Class 2-various professionals; Class 3-corporate managers, associate professionals, and the armed forces; Class 4-trade workers, plant operators and office clerks; Class 5-other trade workers, machine operators and labourers; and Class 6-market-orientated agricultural and fishery workers. Classes 1 to 3 and were combined due to their small numbers. Education was classified as no tertiary educa- 
tion, Certificate (e.g. Trade or Technicians, Apprenticeship or Typing), Diploma (e.g. Teacher, Nurse, or Business Management), or University degree (e.g. MA, PhD, BA, BSc, or Medicine). Combined yearly household income categories were missing, $<\$ 30,000, \$ 30,001$ to $<\$ 50,000, \$ 50,001$ to $\$ 70,000$; and $>\$ 70,000$. After geocoding the address of each participant, the 10 category NZDep2001 was assigned as described by Salmond and Crampton [9].

Resting metabolic rate, the total minimal activity of all tissue cells of the body under steady state conditions, is expressed as the rate of heat production or oxygen consumption related to some unit of body size [10]. Resting metabolic rate (RMR) was calculated using standard equations [11]. Minimal requirements for the ratio of total energy intake (MJ) to resting metabolic rate (EI/RMR) is 1.55 by WHO criteria and 1.38 according to Goldberg et al. [12]. This assesses the degree of any underreporting and was included to determine whether there was differential under-reporting between any of the socioeconomic status groups.

Food intake over the previous 3 months was estimated by a 142-item food frequency questionnaire (FFQ) that included commonly eaten Maori and Pacific Islands foods (e.g. mutton flaps, povi masima, pipis, mussels, oysters, coconut cream, green bananas, puha, kumara, yam, taro tuber, and Maori bread). The FFQ was filled in by participants at their home, and checked for errors and omissions at their interview the following morning. Serving sizes of vegetables, meat, fish and cake were assessed using colour photographs of foods which participants used to rank themselves into three portion size groups (more, same, less). These were scaled as less 0.5, same 1.0, and more 1.6. Otherwise natural serving sizes, such as the average weight of a piece of fruit, or slice of bread were used or published serve sizes [13]. The comprehensive version of the food composition tables [14] was used to calculate nutrient intakes. Cups of milk included milk added to coffee and tea, glasses of milk drunk and milk added to breakfast cereals. We have previously reported that this FFQ was valid and reproducible in European, and Maori and Pacific participants [15].

\subsection{Data Analysis}

Participant data were weighted according to the sampling frame that they were obtained from using dual frame sampling methodology [16]-[18] using SAS survey procedures [19]. Geometric means were first calculated after adjusting for age, ethnicity and gender; and in the second step, NZSEI96, income, education and NZDep2001 were entered to estimate their independent effects. Because of the positively skewed frequency distribution of the dietary nutrients and food servings, these were converted to $\log _{e}$ values for calculations; the results are presented as geometric means (the exponential of the mean of the logged data) and associated $95 \%$ tolerance factor.

\section{Results}

Income showed the highest correlations with both NZSEI96 and NZDep2001 (both 0.37). The correlation between the NZSEI96 and NZDep2001 was 0.34, and between NZSEI96 and education was 0.24. The correlations between NZDep2001 and education $(r=0.18)$ and income and education $(r=0.16)$ were lowest.

\subsection{Income}

Geometric mean nutrient intakes, adjusted for age, gender and ethnicity by household income are shown in Table 1. Compared to people with incomes $\geq \$ 70,001$, carbohydrate and starch intakes were higher in those with an income of $\$ 30-\$ 50,000$, and were no longer significant after adjusting for other SES measures. However, there were higher cholesterol intakes in the $\$ 30-\$ 50,000$ and $<\$ 30,000$ income groups and alcohol intakes were lower in all of the lower income groups. These latter associations remained significant after adjusting for all other SES measures.

Nutrients expressed as their contribution to total energy intakes by household income are shown in Table 2 . Alcohol intakes were significantly lower in all lower income groups and the missing group compared to the highest, and calcium intakes were lower in the $<\$ 30,000$ income group. Initially higher starch intakes in the lowest income group; higher carbohydrate intakes in the missing group; and lower fibre intakes in the \$30 $\$ 50,000$ income group were no longer significant after adjusting for NZDep2001, and lower calcium intakes in the $\$ 50$ - \$70,000 and missing income groups were no longer significant after all other SES measures were included in the model. The lowest income group had lower fibre and calcium intakes compared to the highest income group. 
Table 1. Geometric mean (95\% tolerance factor) daily nutrient intakes by household income adjusted for age, gender and ethnicity.

\begin{tabular}{|c|c|c|c|c|c|}
\hline & \multicolumn{5}{|c|}{ Household Income } \\
\hline & $\geq \$ 70,001$ & $\$ 50-\$ 70,000$ & $\$ 30-\$ 50,000$ & $<\$ 30,000$ & Missing \\
\hline Number & 1206 & 846 & 635 & 981 & 339 \\
\hline Energy (MJ) & $9.1(1.03)$ & $9.3(1.04)$ & 9.5 (1.04) & $9.3(1.04)$ & $9.1(1.07)$ \\
\hline EI/RMR [mean(se)] & $1.38(0.03)$ & $1.41(0.03)$ & $1.48(0.03)$ & $1.49(0.03)$ & $1.44(0.05)$ \\
\hline Carbohydrate (g) & $248(1.03)$ & $257(1.04)$ & $265(1.04)^{* \dagger}$ & $262(1.04)$ & $264(1.07)$ \\
\hline Starch (g) & $126(1.04)$ & $130(1.05)$ & $136(1.05)^{* \dagger}$ & $135(1.05)$ & $131(1.07)$ \\
\hline Sucrose (g) & 47 (1.05) & $50(1.06)$ & $50(1.06)$ & $49(1.07)$ & $53(1.12)$ \\
\hline Fibre (g) & $24(1.04)$ & $23(1.05)$ & $23(1.05)$ & $22(1.05)$ & $23(1.08)$ \\
\hline Protein (g) & 93 (1.03) & $94(1.04)$ & $98(1.04)$ & $97(1.05)$ & $91(1.08)$ \\
\hline Fat (g) & $86(1.04)$ & $88(1.04)$ & $90(1.04)$ & $88(1.04)$ & 84 (1.09) \\
\hline SFA (g) & $32(1.04)$ & $34(1.05)$ & 35 (1.05) & $34(1.05)$ & $33(1.10)$ \\
\hline PUFA (g) & $13(1.04)$ & $13(1.05)$ & $13(1.05)$ & $13(1.05)$ & $12(1.09)$ \\
\hline MUFA (g) & $31(1.04)$ & $31(1.04)$ & $31(1.05)$ & $30(1.05)$ & $29(1.09)$ \\
\hline Cholesterol (mg) & $328(1.05)$ & $354(1.05)$ & $374(1.06)^{* *}$ & $379(1.07)^{*}$ & $322(1.15)$ \\
\hline Alcohol (g) & $5.1(1.10)$ & $3.2(1.12)^{* *}$ & $2.5(1.11)^{* *}$ & $1.7(1.09)^{* *}$ & $1.9(1.22)^{* *}$ \\
\hline Calcium (mg) & $826(1.04)$ & 799 (1.05) & $824(1.05)$ & $770(1.05)$ & $766(1.09)$ \\
\hline
\end{tabular}

${ }^{*} \mathrm{P}<0.01 ;{ }^{* *} \mathrm{P}<0.001$ compared to income $\geq \$ 70,001$. EI/RMR = total energy intake divided by resting metabolic rate; SFA = saturated fatty acids; PUFA = polyunsaturated fatty acids; MUFA = monounsaturated fatty acids. ${ }^{\dagger}$ No longer significant after adjusting for NZSEI96, education and NZDep2001.

Table 2. Geometric mean (95\% tolerance factor) daily nutrient intakes expressed as a percentage contribution to total energy intakes by household income adjusted for age, gender and ethnicity.

\begin{tabular}{|c|c|c|c|c|c|}
\hline & \multicolumn{5}{|c|}{ Household Income } \\
\hline & $\geq \$ 70,001$ & $\$ 50-\$ 70,000$ & $\$ 30-\$ 50,000$ & $<\$ 30,000$ & Missing \\
\hline Number & 1206 & 846 & 635 & 981 & 339 \\
\hline Carbohydrate (\%) & $46.6(1.01)$ & $47.3(1.02)$ & $47.6(1.02)$ & $47.9(1.02)$ & $49.1(1.03)^{*+}$ \\
\hline Starch (\%) & $23.6(1.03)$ & $23.9(1.03)$ & $24.4(1.03)$ & $24.8(1.03)^{* \dagger}$ & $24.4(1.05)$ \\
\hline Sucrose (\%) & $8.8(1.04)$ & $9.1(1.05)$ & $8.9(1.05)$ & $9.0(1.05)$ & 9.9 (1.09) \\
\hline Fibre (g/MJ) & $2.6(1.03)$ & $2.5(1.04)$ & $2.5(1.04)^{* \dagger}$ & $2.1(1.04)^{* *}$ & $2.5(1.08)$ \\
\hline Protein (\%) & $16.4(1.02)$ & $16.3(1.02)$ & $16.5(1.02)$ & $16.6(1.02)$ & $16.0(1.03)$ \\
\hline Fat (\%) & $34.9(1.01)$ & $35.4(1.02)$ & $35.1(1.02)$ & $35.0(1.02)$ & 34.1 (1.04) \\
\hline SFA (\%) & $13.2(1.02)$ & $13.6(1.03)$ & $13.6(1.02)$ & $13.6(1.02)$ & $13.2(1.05)$ \\
\hline PUFA (\%) & $5.2(1.03)$ & $5.2(1.03)$ & $5.1(1.03)$ & $5.0(1.03)$ & $5.0(1.05)$ \\
\hline MUFA (\%) & $12.5(1.02)$ & $12.4(1.02)$ & $12.3(1.02)$ & $12.1(1.02)$ & $11.8(1.04)$ \\
\hline Cholesterol (mg/MJ) & $36.2(1.04)$ & $38.3(1.05)$ & $39.5(1.05)^{*}$ & $40.8(1.05)^{* *}$ & $35.2(1.12)$ \\
\hline Alcohol (\%) & $2.0(1.07)$ & $1.3(1.08)^{* *}$ & $1.0(1.08)^{* *}$ & $0.8(1.06)^{* *}$ & $0.9(1.14)^{*}$ \\
\hline Calcium (mg/MJ) & $91.0(1.02)$ & $86.3(1.03)^{*}$ & $87.0(1.03)$ & $82.8(1.03)^{* *}$ & $83.8(1.05)^{*+}$ \\
\hline
\end{tabular}

${ }^{*} \mathrm{P}<0.01 ;{ }^{* *} \mathrm{P}<0.001$ compared to income $\geq \$ 70,001$. SFA = saturated fatty acids; PUFA = polyunsaturated fatty acids; MUFA = monounsaturated fatty acids. ${ }^{\dagger}$ No longer significant after adjusting for NZSEI96, education and NZDep2001. 
Geometric mean food group servings by household income are shown in Table 3 after adjusting for age, gender, ethnicity and total energy intakes. Compared to the highest income group, lower vegetable, fruit, cheese, milk and spirit servings were observed in the lowest income group. Cereal servings were significantly lower in the two lowest income groups, and wine servings were lower in all three lower income groups compared to the highest. The significantly lower vegetable servings in the $\$ 40$ - $\$ 50,000$ income group was no longer significant after all other SES measures were in the model; the lower number of slices of bread in the two lowest income groups, the lower spirit servings in the second to lowest income group and the lower beer servings in the lowest income group were no longer significant after adjusting for both NZDep2001 and NZSEI96.

Apart from lower alcohol intakes in people with missing income compared to the highest income group (Table 1 and Table 2), no clear dietary pattern was observed. In contrast, milk, cheese, cereal, wine, beer and spirit servings were lower in people with missing income compared to the highest income group (Table 3).

\subsection{NZDep2001}

Geometric mean nutrient intakes, adjusted for age, gender and ethnicity, by NZDep2001 are shown in Table 4. Compared to the highest NZDep2001 class (1 \& 2), alcohol intakes were lower in all other NZDep2001. However, initially significantly lower fibre intakes in NZDep2001 class 7 \& 8, lower alcohol intakes in NZDep2001 class 3 \& 4 and lower calcium intakes in NZDep2001 class 9 \& 10 were no longer significant after further adjusting for income.

Table 5 shows nutrient intakes expressed as their contribution to total energy intakes by NZDep2001 after adjusting for age, gender and ethnicity. Independent associations included higher starch and lower calcium intakes in the lowest NZDep2001 class and lower alcohol intakes in the two lowest NZDep2001 classes compared to the highest $(1 \& 2)$. Initially significantly lower alcohol intakes in NZDep2001 classes $3 \& 4$ and $5 \& 6$ and lower calcium intakes in NZDep2001 class 5 \& 6 were no longer significant after adjusting for income; and the higher starch intakes in NZDep2001 class 7 \& 8 were no longer significant after income and education were included in the model.

Geometric mean food group servings by NZDep2001 are shown in Table 6 after adjusting for age, gender, ethnicity and total energy intakes. People in the lowest NZDep2001 class had higher servings of chicken, fish, eggs and bread and lower servings of cheese compared to the highest NZDep2001 class. Fruit servings were lower in the two lowest NZDep2001 classes, spirit servings were lower in the three lowest NZDep2001 classes and wine servings were lower in all four lower NZDep2001 classes compared to the highest. Initially significant lower vegetable servings in the three lowest NZDep2001 classes were no longer significant after income and education or income and NZSEI96 were included in the model, and the lower milk, cereal and beer servings in NZDep2001 class 9 \& 10 and the lower cheese servings in NZDep2001 class 7 \& 8 were no longer significant when income was included in the model.

\subsection{NZSEI96}

There were few associations between NZSEI96 and nutrient intakes (individual data not shown). Although carbohydrate and starch intakes were higher in NZSEI96 class 6, and alcohol intakes lower in NZSEI96 classes 5 and 6, compared to NZSEI96 class 1 \& 2 \& 3, only alcohol intakes in NZSEI96 class 6 remained significant after adjusting for the other SES measures.

When nutrients were expressed as their percentage contribution to total energy intakes, independent associations with NZSEI96 were significantly higher carbohydrate intakes and lower alcohol and monounsaturated fatty acid intakes in NZSEI96 class 6 compared to NZSEI96 class 1 \& 2 \& 3 (individual data not shown). Initially significantly lower alcohol intakes in NZSEI96 class 5 were explained by income; and the lower calcium intakes in NZSEI96 classes 5 and 6 were explained by income or NZDep2001.

There were significant independent associations of NZSEI96 with a higher number of slices of bread in NZSEI96 class 6, lower wine servings in NZSEI96 classes 4 to 6, and lower spirits servings in NZSEI96 class 4 compared to NZSEI96 class 1 \& 2 \& 3 (individual data not shown). Initially lower vegetable, cereal and cheese servings in NZSEI96 class 6 compared to NZSEI96 class 1 \& 2 \& 3 were no longer significant after adjusting for income or NZDep2001; and the higher number of slices of bread in NZSEI96 class 5 was no longer significant after adjusting for all other SES measures together. 
Table 3. Geometric mean (95\% tolerance factor) servings of food groups per month adjusted for age, gender, ethnicity and total energy intake by level of household income.

\begin{tabular}{|c|c|c|c|c|c|}
\hline & \multicolumn{5}{|c|}{ Household Income } \\
\hline & $\geq \$ 70,001$ & $\$ 50-\$ 70,000$ & $\$ 30-\$ 50,000$ & $<\$ 30,000$ & Missing \\
\hline Number & 1206 & 846 & 635 & 981 & 339 \\
\hline Red meat & $27.8(1.06)$ & $26.4(1.08)$ & $26.0(1.07)$ & 23.7 (1.09) & $22.6(1.23)$ \\
\hline Chicken & $3.7(1.06)$ & $4.1(1.08)$ & $4.1(1.08)$ & $4.2(1.09)$ & 3.8 (1.17) \\
\hline Fish & $7.1(1.06)$ & $6.6(1.08)$ & $7.0(1.08)$ & 6.7 (1.09) & $6.0(1.18)$ \\
\hline Vegetables & $141.5(1.03)$ & $132.3(1.05)$ & $129.0(1.04)^{* *+}$ & $122.7(1.05)^{* * *}$ & 139.5 (1.09) \\
\hline Fruit & $55.5(1.07)$ & $51.2(1.10)$ & $47.3(1.11)$ & $40.5(1.10)^{* *}$ & $48.4(1.24)$ \\
\hline Eggs & $6.8(1.07)$ & 7.5 (1.09) & $7.8(1.08)$ & $7.3(1.10)$ & $6.2(1.16)$ \\
\hline Cheese $^{1}$ & $10.2(1.09)$ & $8.6(1.10)$ & $9.0(1.10)$ & $6.3(1.11)^{* * *}$ & $5.7(1.22)^{* * *}$ \\
\hline Milk & $68.6(1.13)$ & $61.6(1.17)$ & $53.7(1.16)$ & $47.5(1.17)^{* *}$ & $37.1(1.39)^{* * *}$ \\
\hline Bread & $17.2(1.05)$ & $18.8(1.08)$ & $19.9(1.07)^{* \dagger}$ & $20.3(1.08)^{* * \dagger}$ & $20.2(1.18)$ \\
\hline Cereal & $10.2(1.11)$ & $8.5(1.14)$ & $7.3(1.14)^{* *}$ & $6.1(1.14)^{* *}$ & $5.2(1.26)^{* *}$ \\
\hline Wine & $7.8(1.11)$ & $3.8(1.14)^{* *}$ & $2.7(1.12)^{* * *}$ & $2.0(1.13)^{* * *}$ & $2.1(1.27)^{* * *}$ \\
\hline Beer & $2.4(1.09)$ & $2.1(1.11)$ & $1.9(1.12)$ & $1.6(1.12)^{* *+}$ & $1.5(1.21)^{*}$ \\
\hline Spirits & $1.5(1.10)$ & $1.2(1.11)$ & $1.0(1.11)^{* \dagger}$ & $0.7(1.09)^{* *}$ & $0.7(1.17)^{* * *}$ \\
\hline
\end{tabular}

${ }^{*} \mathrm{P}<0.01 ;{ }^{* *} \mathrm{P}<0.001$ compared to income $\geq \$ 70,001 .{ }^{1}$ Excludes cottage cheese. ${ }^{\dagger}$ No longer significant after adjusting for NZSEI96, NZDep2001 and education.

Table 4. Geometric mean (95\% tolerance factor) daily nutrient intakes by NZDep2001 group adjusted for age, gender and ethnicity.

\begin{tabular}{|c|c|c|c|c|c|}
\hline & \multicolumn{5}{|c|}{ NZDep2001 } \\
\hline & $1 \& 2$ & $3 \& 4$ & $5 \& 6$ & $7 \& 8$ & $9 \& 10$ \\
\hline Number & 726 & 642 & 654 & 792 & 1193 \\
\hline Energy (MJ) & $9.8(1.04)$ & $9.6(1.04)$ & $9.6(1.04)$ & $9.6(1.04)$ & $9.8(1.04)$ \\
\hline EI/RMR [mean(se)] & $1.52(0.03)$ & $1.50(0.03)$ & $1.51(0.03)$ & $1.53(0.04)$ & $1.52(0.03)$ \\
\hline Carbohydrate (g) & $284(1.04)$ & $279(1.04)$ & $283(1.05)$ & $283(1.05)$ & $288(1.04)$ \\
\hline Starch (g) & $133(1.04)$ & $133(1.04)$ & 134 (1.05) & 138 (1.05) & $144(1.04)$ \\
\hline Sucrose (g) & $61(1.08)$ & $61(1.07)$ & $61(1.08)$ & 57 (1.09) & $58(1.07)$ \\
\hline Fibre (g) & $27(1.05)$ & $26(1.05)$ & $26(1.05)$ & $25(1.05)^{* \dagger}$ & $26(1.06)$ \\
\hline Protein (g) & $95(1.04)$ & $91(1.04)$ & $93(1.04)$ & $93(1.05)$ & $98(1.04)$ \\
\hline Fat (g) & $90(1.04)$ & 89 (1.04) & $86(1.05)$ & 87 (1.05) & 89 (1.05) \\
\hline SFA (g) & $34(1.04)$ & $34(1.05)$ & $32(1.06)$ & $34(1.06)$ & $34(1.05)$ \\
\hline PUFA (g) & $13(1.05)$ & $13(1.05)$ & $13(1.05)$ & $13(1.06)$ & $13(1.05)$ \\
\hline MUFA (g) & $32(1.04)$ & $32(1.05)$ & $30(1.05)$ & $30(1.06)$ & $30(1.05)$ \\
\hline Cholesterol (mg) & $343(1.05)$ & $322(1.05)$ & $340(1.07)$ & $346(1.08)$ & $371(1.06)$ \\
\hline Alcohol (g) & $4.9(1.12)$ & $3.6(1.13)^{* * \dagger}$ & $3.1(1.13)^{* *}$ & $2.2(1.12)^{* *}$ & $1.7(1.11)^{* *}$ \\
\hline Calcium (mg) & $864(1.05)$ & $813(1.04)$ & 797 (1.06) & $801(1.06)$ & $789(1.05)^{* \dagger}$ \\
\hline
\end{tabular}

${ }^{*} \mathrm{P}<0.01 ;{ }^{* * *} \mathrm{P}<0.001$ compared to NZDep2001 $1 \& 2$. EI/RMR = total energy intake divided by resting metabolic rate; SFA = saturated fatty acids; PUFA = polyunsaturated fatty acids; MUFA = monounsaturated fatty acids. ${ }^{\dagger}$ No longer significant after adjusting for NZSEI96, income and education. 
Table 5. Geometric mean (95\% tolerance factor) daily nutrient intakes expressed as a percentage contribution to total energy intakes by NZDep2001 group adjusted for age, gender and ethnicity.

\begin{tabular}{|c|c|c|c|c|c|}
\hline & \multicolumn{5}{|c|}{ NZDep2001 } \\
\hline & $1 \& 2$ & $3 \& 4$ & $5 \& 6$ & $7 \& 8$ & $9 \& 10$ \\
\hline Number & 726 & 642 & 654 & 792 & 1193 \\
\hline Carbohydrate (\%) & $49.0(1.02)$ & $49.3(1.02)$ & $50.1(1.02)$ & $50.2(1.02)$ & $50.1(1.02)$ \\
\hline Starch (\%) & $23.0(1.03)$ & $23.5(1.03)$ & $23.7(1.03)$ & $24.5(1.03)^{* \dagger}$ & $25.1(1.03)^{* *}$ \\
\hline Sucrose (\%) & $10.5(1.06)$ & $10.9(1.05)$ & $10.7(1.06)$ & $10.1(1.07)$ & $10.1(1.05)$ \\
\hline Fibre (g/MJ) & $2.8(1.04)$ & $2.7(1.04)$ & $2.7(1.04)$ & $2.6(1.04)$ & $2.6(1.04)$ \\
\hline Protein (\%) & $15.5(1.02)$ & $15.1(1.02)$ & $15.5(1.03)$ & $15.5(1.03)$ & $16.0(1.02)$ \\
\hline Fat (\%) & $33.7(1.02)$ & $34.3(1.02)$ & $32.9(1.02)$ & $33.7(1.02)$ & $33.6(1.02)$ \\
\hline SFA (\%) & $12.6(1.02)$ & $13.0(1.02)$ & $12.4(1.03)$ & $13.0(1.03)$ & $13.0(1.03)$ \\
\hline PUFA (\%) & $5.0(1.03)$ & $5.0(1.03)$ & $4.9(1.04)$ & $4.9(1.04)$ & $5.0(1.03)$ \\
\hline MUFA (\%) & $12.1(1.02)$ & $12.2(1.02)$ & $11.6(1.03)$ & $11.7(1.03)$ & $11.5(1.02)^{*+}$ \\
\hline Cholesterol (mg/MJ) & $34.9(1.05)$ & 33.5 (1.04) & $35.3(1.06)$ & $36.2(1.06)$ & $38.0(1.05)$ \\
\hline Alcohol (\%) & $1.9(1.08)$ & $1.4(1.08)^{* \dagger}$ & $1.3(1.09)^{* *+}$ & $0.9(1.07)^{* *}$ & $0.7(1.07)^{* *}$ \\
\hline Calcium (mg/MJ) & $87.9(1.03)$ & $84.6(1.03)$ & $82.8(1.03)^{* \dagger}$ & $83.7(1.03)$ & $80.8(1.03)^{* *}$ \\
\hline
\end{tabular}

${ }^{*} \mathrm{P}<0.01 ;{ }^{* *} \mathrm{P}<0.001$ compared to NZDep2001 1 \& 2. EI/RMR = total energy intake divided by resting metabolic rate; SFA = saturated fatty acids; PUFA = polyunsaturated fatty acids; MUFA = monounsaturated fatty acids. ${ }^{\dagger}$ No longer significant after adjusting for NZSEI, income and education.

Table 6. Mean (se) servings of food groups per month by NZDep2001 group adjusted for age, gender and ethnicity and total energy.

\begin{tabular}{|c|c|c|c|c|c|}
\hline & \multicolumn{5}{|c|}{ NZDep2001 } \\
\hline & $1 \& 2$ & $3 \& 4$ & $5 \& 6$ & $7 \& 8$ & $9 \& 10$ \\
\hline Number & 726 & 642 & 654 & 792 & 1193 \\
\hline Red meat & $25.9(1.07)$ & $25.3(1.07)$ & $26.1(1.06)$ & $26.1(1.09)$ & $25.8(1.08)$ \\
\hline Chicken & 3.7 (1.06) & $4.0(1.08)$ & $3.8(1.08)$ & 3.8 (1.09) & $4.8(1.09)^{* *}$ \\
\hline Fish & 7.5 (1.07) & $6.1(1.08)$ & 6.4 (1.09) & 6.5 (1.09) & $7.8(1.09)^{* *}$ \\
\hline Vegetables & $142.2(1.04)$ & $133.9(1.04)$ & $130.8(1.05)^{* \dagger}$ & $127.1(1.05)^{* * \dagger}$ & $126.2(1.05)^{* * \dagger}$ \\
\hline Fruit & $58.8(1.08)$ & $50.0(1.10)^{*}$ & $48.6(1.10)^{* \dagger}$ & $42.9(1.11)^{* *}$ & $41.3(1.12)^{* *}$ \\
\hline Eggs (number) & $7.4(1.08)$ & $6.3(1.09)$ & $7.6(1.10)$ & $7.0(1.11)$ & $7.9(1.11)^{*}$ \\
\hline Cheese $^{1}$ & $10.2(1.09)$ & $9.9(1.10)$ & $8.6(1.10)$ & $7.7(1.12)^{* * \dagger}$ & $4.9(1.12)^{* *}$ \\
\hline Milk (cups per mth) & $63.8(1.14)$ & $56.4(1.17)$ & $59.4(1.16)$ & $56.1(1.20)$ & $47.2(1.17)^{* \dagger}$ \\
\hline Bread (slices) & $16.7(1.06)$ & $18.1(1.07)$ & $18.9(1.07)^{* \dagger}$ & $19.4(1.09)^{* \dagger}$ & $23.5(1.09)^{* *}$ \\
\hline Cereal & $9.0(1.12)$ & $9.0(1.13)$ & $8.0(1.14)$ & 7.3 (1.17) & $6.0(1.15)^{* * \dagger}$ \\
\hline Wine & $7.2(1.13)$ & $4.8(1.15)^{* *}$ & $3.9(1.14)^{* *}$ & $2.4(1.14)^{* *}$ & $1.5(1.12)^{* *}$ \\
\hline Beer & $2.2(1.11)$ & $2.1(1.11)$ & $2.3(1.13)$ & $1.8(1.13)$ & $1.6(1.13)^{* \dagger}$ \\
\hline Spirits & $1.6(1.12)$ & $1.1(1.11)^{* \dagger}$ & $1.0(1.11)^{* *}$ & $0.9(1.11)^{* *}$ & $0.6(1.09)^{* *}$ \\
\hline
\end{tabular}

${ }^{*} \mathrm{P}<0.01 ;{ }^{* *} \mathrm{P}<0.001$ compared to NZDep2001 1 \& 2. EI/RMR = total energy intake divided by resting metabolic rate; SFA = saturated fatty acids; PUFA = polyunsaturated fatty acids; MUFA = monounsaturated fatty acids. ${ }^{\dagger}$ No longer significant after adjusting for NZSEI, income and education. ${ }^{1}$ Excludes low fat cheese.

\subsection{Education}

There were no significant differences in nutrient intakes by education (individual data not shown). When nutrients were expressed as their contribution to total energy intakes, protein intakes were significantly higher in people with a Certificate education and no tertiary education groups compared to those with a University degree. However, protein intakes in people with a Certificate education were no longer significant after adjusting for the 
other SES measures. In addition, calcium intakes expressed as $\mathrm{mg} / \mathrm{KJ}$ were significantly higher in people with a Certificate education compared to those with a University degree. Red meat servings were significantly higher in Certificate educated people compared to University educated people (individual data not shown), and fruit intakes were lower in those with no tertiary education. The higher bread and lower and milk servings in those with a Certificate and no tertiary education were no longer significant after adjusting for income or NZDep2001, as were the lower vegetable, cheese, cereal, and wine servings in those with no tertiary education compared to those with a university education.

\section{Discussion}

The current study has shown that income and NZDep2001 had stronger associations with dietary intakes than with the occupation based NZSEI96 and education. Many of the initially significant associations with income were explained by NZDep2001, and vice versa suggesting that they were capturing similar aspects of the diet. Income showed more associations with nutrient intakes and NZDep2001 more associations with food group servings. We have previously reported that the NZSEI91 and education were associated with food group selections, whereas nutrient intakes were associated with income [5], as found in the current study. The relationship between diet and NZDep2001 does not appear to have been reported previously. In the current study the associations between diet and NZDep2001 were stronger than with NZSEI96 or education.

When nutrients were expressed as their percentage contribution to total energy intakes and adjusted for age, gender, ethnicity, and other SES measures, intakes of cholesterol were higher in the lower income groups, and fibre, alcohol and calcium were lower compared to the highest income group. Similarly adjusted nutrients expressed as their contribution to total energy intakes showed less alcohol servings in the lower NZDep2001 classes compared to the highest NZDep2001 class.

Compared to the highest income group, age, gender, ethnicity, total energy intakes and other SES measures, showed lower vegetable, fruit, cheese, milk, cereal, wine and spirit servings in the lower income groups. Similarly adjusted food groups showed that higher servings of chicken and bread and lower servings of fruit, cheese, wine and spirit servings in the lowest NZDep2001 class compared with the highest NZDep2001 group, and higher chicken and egg servings in the lower NZDep2001 classes.

Although NZDep2001 is area-based, rather than an individual SES measure, reports have documented differences in availability and the price of foods across neighborhoods, that grocery "environments" are related to dietary practices of individuals [20] [21] and that access to fast food outlets was closer in lower compared to higher socioeconomic areas [22]. In Britain, intakes of fruit and vegetables were higher in the highest compared with the lowest income groups [23] [24], education groups [25] and income and an area-based measure of SES [26]. Amuza et al. have reported that both area deprivation and lifecourse socioeconomic position were independent predictors of eating fruit and vegetables [27]. In contrast, Giskes et al. reported that individual SES was stronger for food choice, breakfast and fruit consumption than an area-based SES [28]. For people on low incomes, the extra cost of a nutritious diet is likely to be an additional obstacle to healthy eating.

Lower socio-economic status, (measured by Carstair's quintile, the occupation based social class index, employment status and education) was found to be associated with lower cereal (in men and women) and vegetable consumption (in men only) in Scotland [29]. In the USA, individual level income was a more consistent predictor of diet than neighborhood income [30], though there appeared to be significantly lower intakes of fruit and vegetables and fish in the lower income strata. An Australian survey reported lower intakes of fruit in the lower occupational category, education and income groups, lower alcohol intakes (not with education), cereal and fibre (both not with income), and lower cheese intake (not by occupational category) [31].

The New Zealand National Nutrition Survey (NNS) carried out in 1997 reported lower dietary fibre, calcium, alcohol, cheese and fruit servings in the lower NZDep96 classes compared to the highest NZDep96 class, but no associations with total energy intakes, fat, SFA or cholesterol [32]. With the exception of dietary fibre intakes which were associated with income, the findings in the current survey using NZDep2001 are similar. Although we cannot compare food servings with the NNS as results were expressed as the proportion of people eating at least one serve per week, some food groups were mentioned in the text as having a significant socioeconomic gradient [32].

The 1989-1990 Life In New Zealand (LINZ) survey reported lower cheese, wine and spirits servings and higher egg servings in men only in the lower education groups compared to the highest [33]. The LINZ survey 
also reported higher egg servings in men only and lower wine and spirit (men only) servings in the lower ElleyIrving SES classes compared to the highest class [33].

\subsection{Associations with NZSEI96}

In the current study we found few independent associations between NZSEI96 and crude nutrient intakes. However, age, gender, ethnicity and other SES measures adjusted nutrients expressed as their contribution to total energy intakes showed higher carbohydrate intakes and lower fibre, MUFA, and alcohol intakes in the lowest NZSEI96 group compared to the highest. Wine servings were also lower in the lowest NZSEI96 group and bread servings higher compared to the highest group. We have previously reported that low NZSEI91 was independently associated with higher dietary cholesterol intakes, and higher egg and beer servings, and lower cheese, milk and wine servings in a working population [5]. The reasons for these discrepancies are unclear, but may have been due to 1) NZSEI96 classes 1 to 3 were combined due to their small numbers, rather than NZSEI91 classes of 1 and 2 that were combined in the earlier study [5]; 2) that it used the NZSEI91 coding [3] rather than the NZSEI96 coding of occupations used here [8]; 3) that it was a working population; 4) that approximately $72 \%$ were men in the previous study compared to approximately $50 \%$ in the current study; or 5) that it comprised 79.2\% Europeans compared to 50\% in the current survey. Certainly, the correlation between NZSEI91 occupational class and education $(r=0.49)$ was higher in the previous study, but similar between NZSEI91 and income $(r=0.35)$ in the previous study compared to the current study $(r=0.24$, and $r=0.37$, respectively).

\subsection{Associations with Education}

There were few significant associations between education and dietary intakes in the current study. We have previously reported lower fibre and calcium intakes in those with no tertiary education compared to those with a tertiary education [5], but no associations with the percentage contribution of nutrients to total energy intakes. There were also lower servings of vegetables, cheese, milk, and wine, and higher servings of eggs, bread, cereal and beer in the no tertiary education group compared to the University educated group in this working population [5]. The correlation between income and education was lower in the current study $(r=0.16)$ than the previous study $(r=0.28)$ [5]. Reasons for the inconsistent findings may include 2) to 5$)$ in the last paragraph.

\subsection{Strengths and Limitations}

The major strengths of the current study are its size, and its community-based sample. A limitation of the FFQ includes its estimation of "true" dietary intakes [34]. It is possible that some participants may over- or underestimate the frequency of food intakes. Compared to the cut-off levels of 1.38 and 1.55 for the EI/RMR [12], there may have been some under-reporting in all socioeconomic status groups (Table 1 and Table 4). However, the EI/RMR levels were similar in all SES groups. This effect of over- and underestimation of energy intake on ethnic comparisons of nutrient intakes is minimized by expressing nutrient intakes as their percentage contribution to total energy intakes (Table 2 and Table 5) and making group comparisons. Any measurement error in the FFQ is likely to be nondifferential, and therefore the expectation would be that the observed associations would be attenuated towards the null.

A major disadvantage of income is that some people refuse to divulge the information and others do not know (Table 1 to Table 3 missing column), however it is easy to measure and code, as is education. In addition, poor health may actually lead to a drop in income.

In contrast, NZSEI is an occupation-based measure that can be difficult to assign to a housewife or a person who has retired or is unemployed. This can be partly overcome by using a past occupation, or the occupation of an employed spouse. In the current survey we have assigned the NZSEI to the higher of the participant or spouse, or for those who had retired to their main life-time occupation. Another disadvantage, compared to income or education, is that the occupation(s) of an individual have to be coded and then mapped onto the NZSEI scale. It can also be difficult to code an occupation if insufficient information is given, such as "Engineer".

A disadvantage of NZDep2001, aside from being an area-based rather than individual-based, is that the address of the participant must be first geocoded using a computer that requires addresses that match those geocoded. In the current study, many people who lived on the border of suburbs chose the next suburb as their 
domicile. Furthermore, NZDep is likely to have a higher misclassification error than the other SES measures as not all deprived people live in deprived small areas, and vice-versa. Despite these limitations, both household income and the area-based NZDep2001 have shown important associations with dietary intakes.

\section{Conclusion}

Income was more strongly associated with nutrient intakes and NZDep2001 with food group servings. However, NZDep2001 and income appear to be measuring different elements of dietary intakes and food group servings, with income being associated with lower vegetable, milk and cereal servings, and increased dietary cholesterol and lower fibre, and calcium intakes and NZDep2001 with increased chicken, eggs and bread servings. Understanding some of the community level barriers to changing diet might lead to more effective interventions to improve health in the whole community, particularly amongst those who are most disadvantaged. Public health efforts to change dietary habits may benefit from further investigation of possible neighborhood level determinants of diet.

\section{Acknowledgements}

We thank the technical and clerical staff who conducted the study so capably and efficiently. This study was funded by the Health Research Council of New Zealand who had no role in the design, collection, analysis or interpretation of the data. We gratefully acknowledge the Ministry of Health (Public Intelligence) and Crop and Food Research for providing a complimentary copy of FOODfiles to assist with dietary assessment.

\section{References}

[1] National Health Committee (1998) The Social, Cultural and Economic Determinants of Health in New Zealand: Action to Improve Health. Ministry of Health, Wellington.

[2] Howden-Chapman, P. and Tobias, M., Eds. (2000) Social Inequalities in Health: New Zealand 1999. Ministry of Health, Wellington.

[3] Davis, P., McLeod, K., Ransom, M. and Ongley, P. (1997) The New Zealand Socioeconomic Index of Occupational Status (NZSEI). Research Report \#2. Statistics New Zealand, Wellington.

[4] Geyer, S., Hemstrom, O., Peter, R. and Vagero, D. (2006) Education, Income, and Occupational Class Cannot Be Used Interchangeably in Social Epidemiology. Empirical Evidence against a Common Practice. Journal of Epidemiology \& Community Health, 60, 804-810. http://dx.doi.org/10.1136/jech.2005.041319

[5] Metcalf, P., Scragg, R. and Davis, P. (2006) Dietary Intakes by Different Markers of Socioeconomic Status: Results of a New Zealand Workforce Survey. New Zealand Medical Journal, 119, U2127.

[6] Statistics New Zealand (2006). http://www.stats.govt.nz/Census/about-2006-census/information-by-variable/ethnicity.aspx

[7] Statistics New Zealand (2001) New Zealand Standard Classification of Occupations 1999. Statistics New Zealand, Wellington.

[8] Davis, P., Jenkin, G. and Coope, P. (2003) New Zealand Socio-Economic Index 1996. An Update and Revision of the New Zealand Socio-Economic Index of Occupational Status. Statistics New Zealand, Wellington.

[9] Salmond, C. and Crampton, P. (2002) NZDep2001 Index of Deprivation User’s Manual. http://www.moh.govt.nz

[10] Bray, G. and Atkinson, R. (1977) Factors Affecting Basal Metabolic Rate. Progress in Food \& Nutrition Science, 2, 395-403.

[11] Schofield, W. (1985) Predicting Basal Metabolic Rate, New Standards and Review of Previous Work. Human Nutrition. Clinical Nutrition, 39, 5-41.

[12] Goldberg, G., Black, A., Jebb, S., Cole, T., Murgatroyd, P., Coward, W., et al. (1991) Critical Evaluation of Energy Intake Data Using Fundamental Principles of Energy Physiology: 1. Derivation of Cut-Off Limits to Identify Under-Recording. European Journal of Clinical Nutrition, 45, 583-599.

[13] Nutrition Section Department of Health (1984) Energy Value of Commonly Used Foods: A Calorie Guide for Slimmers. Department of Health, Wellington.

[14] FOODfiles (2004) Datafiles of the New Zealand Food Composition Database. New Zealand Institute of Crop \& Food Research, Palmerston North.

[15] Metcalf, P.A., Swinburn, B., Scragg, R. and Dryson, E. (1997) Reproducibility and Validity of a Food Frequency Questionnaire in European and Polynesian New Zealanders. Ethnicity \& Health, 2, 297-308. 
http://dx.doi.org/10.1080/13557858.1997.9961838

[16] Lohr, S. and Rao, J. (2000) Inference from Dual Frame Surveys. JASA, 95, 271-280. http://dx.doi.org/10.1080/01621459.2000.10473920

[17] Skinner, C. and Rao, J. (1996) Estimation in Dual Frame Surveys with Complex Designs. JASA, 91, 349-356. http://dx.doi.org/10.1080/01621459.1996.10476695

[18] Metcalf, P. and Scott, A. (2009) Using Multiple Frames in Health Surveys. Statistics in Medicine, 28, $1512-1523$. http://dx.doi.org/10.1002/sim.3566

[19] SAS Institute Inc. (2011) SAS/STAT User’s Guide. Version 9.3. SAS Institute Inc., Cary.

[20] Cheadle, A., Psaty, B., Curry, S., Wagner, E., Diehr, P., Koepsell, T., et al. (1991) Community-Level Comparisons between the Grocery Store Environment and Individual Dietary Practices. Preventive Medicine, 20, 250-261. http://dx.doi.org/10.1016/0091-7435(91)90024-X

[21] Mooney, C. (1990) Cost and Availability of Healthy Food Choices in a London Health District. Journal of Human Nutrition and Dietetics, 3, 111-120. http://dx.doi.org/10.1111/j.1365-277X.1990.tb00058.x

[22] Pearce, J., Blakely, T., Witten, K. and Bartie, P. (2007) Neighbourhood Deprivation and Access to Fast Food Retailing. A National Study. American Journal of Preventive Medicine, 32, 375-382. http://dx.doi.org/10.1016/j.amepre.2007.01.009

[23] James, W., Nelson, M., Ralph, A. and Leather, S. (1997) Socioeconomic Determinants of Health: The Contribution of Nutrition to Inequalities in Health. BMJ, 314, 1545. http://dx.doi.org/10.1136/bmj.314.7093.1545

[24] Boukouvalas, G., Shankar, B. and Traill, W. (2009) Determinants of Fruit and Vegetable Intake in England: A Re-Examination Based on Quantile Regression. Public Health Nutrition, 12, 2183-2191. http://dx.doi.org/10.1017/S1368980009005175

[25] Barker, M., Lawrence, L., Crozier, S., Robinson, S., Baird, J., Margetts, B., et al. (2009) Educational Attainment, Perceived Control and the Quality of Women's Diets. Appetite, 52, 631-636. http://dx.doi.org/10.1016/j.appet.2009.02.011

[26] Diez-Roux, A., Nieto, F., Caulfield, L., Tyroler, H., Watson, R. and Szklo, M. (1999) Neighborhood Differences in Diet: The Atherosclerosis Risk in Communities (ARIC) Study. Journal of Epidemiology \& Community Health, 53, 5563. http://dx.doi.org/10.1136/jech.53.1.55

[27] Amuzu, A., Carson, C., Watt, H., Lawlor, D. and Ebrahin, S. (2009) Influence of Area and Individual Lifecourse Deprivation on Health Behaviours: Findings from the British Women's Heart and Health Study. European Journal of Cardiovascular Prevention \& Rehabilitation, 16, 169-173. http://dx.doi.org/10.1097/HJR.0b013e328325d64d

[28] Giskes, K., Turrell, G., van Lenthe, F., Brug, J. and Mackenbach, J. (2006) A Multilevel Study of Socio-Economic Inequalities in Food Choice Behaviour and Dietary Intake among the Dutch Population: The GLOBE Study. Public Health Nutrition, 9, 75-83. http://dx.doi.org/10.1079/PHN2005758

[29] Gray, L. and Leyland, A. (2008) A Multilevel Analysis of Diet and Socio-Economic Status in Scotland: Investigating the "Glasgow Effect”. Public Health Nutrition, 12, 1351-1358. http://dx.doi.org/10.1017/S1368980008004047

[30] Diez-Roux, A., Nieto, F., Caulfield, L., Tyroler, H., Watso, R. and Szklo, M. (1999) Neigbourhood Differences in Diet: The Atherosclerosis Risk in Communities (ARIC) Study. Journal of Epidemiology \& Community Health, 53, 55-63. http://dx.doi.org/10.1136/jech.53.1.55

[31] Smith, A. and Baghurst, K. (1992) Public Health Implications of Dietary Differences between Social Status and Occupational Category Groups. Journal of Epidemiology \& Community Health, 46, 409-416. http://dx.doi.org/10.1136/jech.46.4.409

[32] Russell, D., Parnell, W., Wilson, N., Faed, J., Ferguson, E., Herbison, P., et al. (1999) NZ Food: NZ People. Key Results of the 1997 National Nutrition Survey. Ministry of Health, Wellington.

[33] Mann, J., Nye, T., Wilson, B., Russell, D., Wilson, N. and Herbison, P. (1991) Life in New Zealand Commission Report, Volume V: Health. University of Otago, Dunedin.

[34] Willett, W. (1990) Nutritional Epidemiology. Monographs in Epidemiology and Biostatistics. Oxford University Press, New York. 